\title{
Somatosensory scaffolding structures
}

\section{Nathaniel A. Jeske*}

Departments of Oral and Maxillofacial Surgery, Pharmacology, University of Texas Health Science Center at San Antonio, TX, USA

\section{Edited by:}

Nikita Gamper, University of

Leeds, UK

Reviewed by:

Guoku Hu, Creighton University,

USA

Lezanne Ooi, University of Western

Sydney, Australia

${ }^{*}$ Correspondence:

Nathaniel A. Jeske, Departments of Oral and Maxillofacial Surgery,

Pharmacology, University of Texas Health Science Center at

San Antonio, 7703 Floyd Curl Dr,

San Antonio, TX 78229-3900, USA

e-mail: Jeske@uthscsa.edu
Dynamic changes in somatosensory perception occur as a result of multiple signaling events. In many instances, over-activation of sensory receptors results in the desensitization and subsequent increased threshold for activation of receptors. In other cases, receptor sensitization can occur following tissue injury and/or inflammation. In both cases, signaling mechanisms that control alterations in receptor activities can significantly affect organism response to sensory stimuli, including thermal, mechanical, and chemical. Due to the homeostatic nature of somatosensory recognition, dynamic changes in receptor response can negatively affect an individual's way of life, as well as alert individuals to tissue damage. Here, we will focus on scaffolding structures that regulate somatosensory neuronal excitability.

Keywords: scaffold, homer, AKAP, lipid raft, pain, afferent, Jeske
Biochemical reactions that modify receptor response posttranslationally are often governed by protein-protein or proteinlipid interactions. In many cases, these reactions are dependent upon substrate/effector proximity, influencing the catalytic conditions required for a biochemical reaction to occur. Certain receptors are modulated by enzymes tethered within close proximity to the receptor through a scaffolding mechanism. The organization of receptors and effectors at the plasma membrane is also influenced by relative associations with discrete domains within the plasma membrane, providing protein-lipid interactions that can also dynamically affect synaptic plasticity. Evolutionary studies on scaffolding proteins indicate expression across multiple species (Emes et al., 2008; Li et al., 2011a), and also suggest that their conserved expression emphasizes their importance in maintaining organism viability. Similarly, plasma membrane lipid variations are present in all mammalian cells, including neurons, and are required for cellular viability. Indeed, the ability of a tissue/system/organism to react to its surroundings indicates an increased likelihood of surviving dynamic environmental changes. Herein, we will discuss certain groups of scaffolding structures that directly associate with and indirectly modify somatosensory receptors responsible for transducing environmental changes to the nervous system.

\section{HOMER SCAFFOLDS}

The family of homer scaffolding proteins consists of three family members: Homer1, Homer2, and Homer3, with respective splice variants for each member. These proteins are typically expressed in a concentrated fashion at post-synaptic densities, but have been ascribed with certain non-neuronal functions (Babu et al., 2004; Stiber et al., 2005). The majority of proteins that belong to the Homer family share two structurally conserved features in their secondary form: an N-terminal enabled/vasodilatorstimulated phosphoprotein homology 1 (EVH1) domain responsible for associating with proline-rich sequences contained within its target/ligand proteins, and a C-terminal coiled-coil domain containing multiple leucine zipper motifs that control homo/heteromerization of Homer proteins (Xiao et al., 1998; Tadokoro et al., 1999). One short Homer protein splice variant, Homer1A, does not contain this C-terminal region (Brakeman et al., 1997), allowing it to exist as a dominant-negative inhibitor to the scaffolding functions of the long forms. Importantly, Homer proteins have been demonstrated to associate with many different proteins, including several which are critical to the transduction of peripheral somatosensory information.

Group 1 metabotropic glutamate receptors (mGluR1/5) expressed in the spinal cord (Yashpal et al., 2001) and amygdala (Neugebauer et al., 2003; Kolber et al., 2010; Li et al., 2011b) have been shown to be important to pain processing, and are tightly modulated by Homer scaffolding proteins (Brakeman et al., 1997; Xiao et al., 1998). As shown in Figure 1, Homer proteins link mGluR1/5 to intracellular calcium stores through inositol-1,4,5trisphosphate $\left(\mathrm{IP}_{3}\right)$ receptor types 1 and 3 (Tu et al., 1998), thereby regulating calcium release and neuronal excitability. Also, Homer proteins are suspected to mediate the coupling of mGluR and $N$-methyl-D-aspartate (NMDA) receptors, prevalent in postsynaptic densities (Guo et al., 2004). Homer proteins associate with numerous other proteins as well, but scaffolding combinations outlined herein have recently been demonstrated to have significant effects on multiple pain models.

The shortened splice variant Homer1A and its dominantnegative ability to associate with target proteins but not scaffold additional Homer proteins, has been demonstrated to be an important mediator of peripheral pain. In 2006, Tappe et al. reported that Homer1A protein expression is significantly greater in activated sensory synapses (Tappe et al., 2006), in agreement with other groups that report neuronal activation-dependent increases in protein expression (Brakeman et al., 1997; Kato et al., 1997; Bottai et al., 2002; Vazdarjanova et al., 2002). For example, short hairpin RNA (shRNA) designed to knock-down Homer1A 


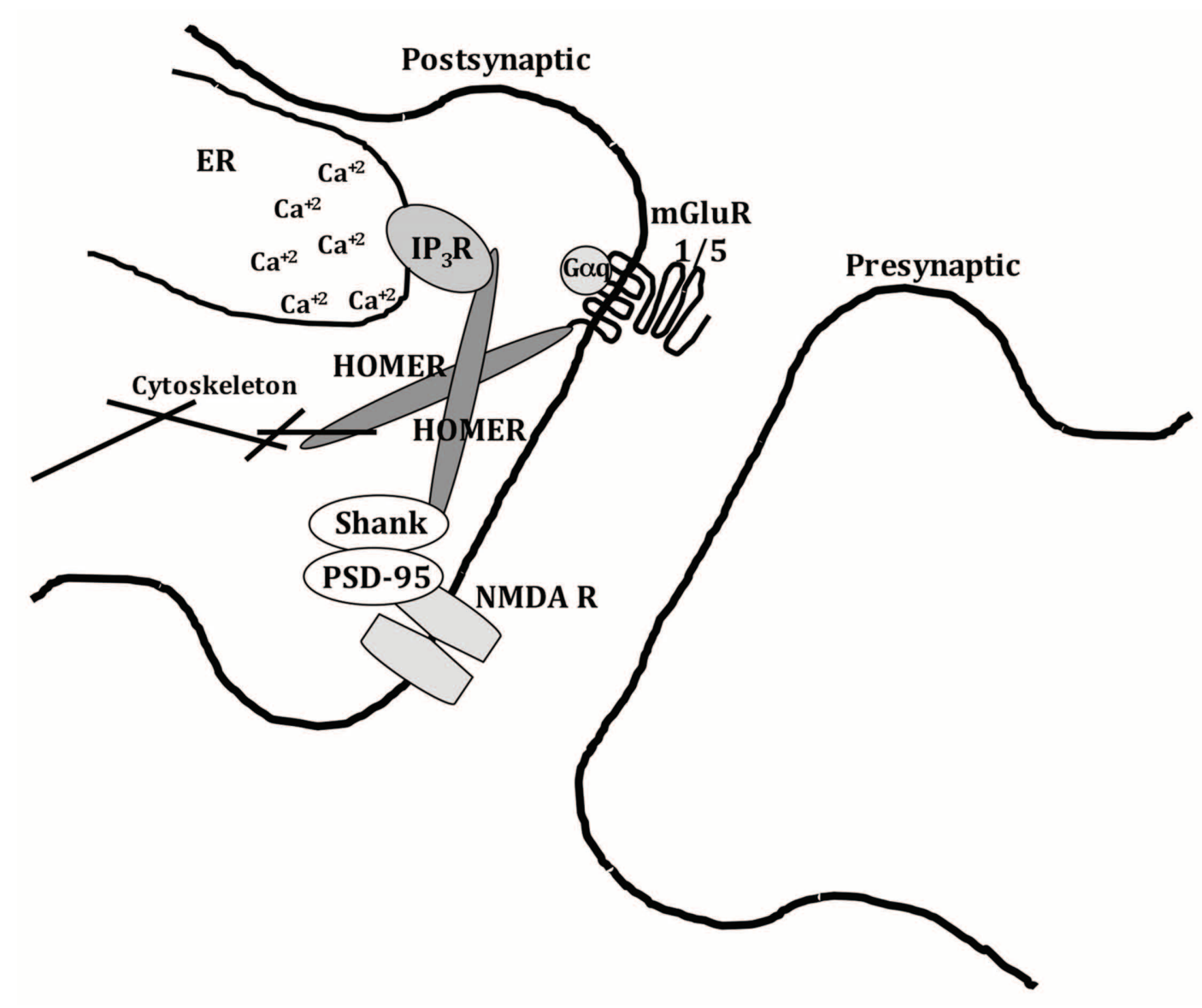

FIGURE 1 | Homer protein scaffolding at post-synaptic synapses. The Homer scaffolding complex links mGluR1/5 receptors to intracellular calcium stores via $\mathrm{IP}_{3}$ receptors, and also links to NMDA receptors to dynamically regulate the transfer of somatosensory information.

protein expression significantly prolongs thermal hyperalgesia following viral administration of CFA-injected animals (Tappe et al., 2006). Indeed, through viral expression of Homer1A, Tappe and colleagues demonstrated that the short splice variant functions as an activity-dependent negative modulator of mGluR scaffolding to intracellular calcium stores. This inhibition can serve as a negative modulator of neuronal sensitization at first afferent pain synapses following peripheral inflammation. In short, Homer1A exists in post-synaptic densities to reduce inflammatory hyperalgesia by preventing the longer Homer proteins from associating with mGluR1/5 and scaffolding other proteins to the receptor.

Multiple groups have since demonstrated that Homer proteins participate as critical modulators of synaptic plasticity as scaffolding proteins. In the amygdala, Homer1A expression reduces arthritic pain hypersensitivity and negatively affects typical changes in interneuron plasticity following an inflammatory challenge (Tappe-Theodor et al., 2011). Further, the induction of chronic compression of the L4/L5 dorsal root ganglia (CCD) induces rapid expression of Homer 1A in the spinal dorsal horn, thereby reducing synaptic plasticity and hence, associated pain (Ma et al., 2009). Given that Homer1A can interfere with intracellular calcium mobilization (Yuan et al., 2003), it could also protect against inflammatory pain and other mGluR-activated signaling mechanisms that influence second-order neuron sensitivity, such as MAPK activation (Ji et al., 2002). Therefore, Homer-dependent scaffolding mechanisms significantly affect afferent pain transduction, serving as an important modulator that could be pharmacologically manipulated in the future to provide therapeutic benefit.

\section{AKAP 79/150}

Neuronal plasticity is predominantly studied as a function of neuronal activation between pre- and post-synaptic neurons in the central nervous system. As the rate of depolarization increases, membrane receptors undergo alterations in expression, posttranslational modification, and/or subcellular localization that directly affect the likelihood of repeated receptor activation, such as for Homer1A-dependent manipulations of mGluR systems. In this scenario, neurons work to endogenously protect the receptor, the terminal, and the neuron itself from potential damage due to over-activation. However, few studies have dissected the molecular changes that occur within the primary afferent terminal at the site of tissue innervation. Recent reports have identified that the scaffolding protein A-kinase anchoring protein 79/150 (AKAP $79 / 150)$ is expressed in the periphery and dynamically recruits 
enzymes to modify Transient Receptor Potential (TRP) receptors, thereby affecting receptor response to stimuli.

Identified in the early 1990s as a scaffolding protein for Protein Kinase A (PKA) (Bregman et al., 1991; Carr et al., 1992), AKAP 79/150 functions to localize certain enzymes to target substrates on a sub-cellular level. In terms of its designations, AKAP79 refers to the human isoform of the scaffolding proteins, expressed at $79 \mathrm{kDa}$ in molecular weight, while AKAP150 is the rodent isoform with additional amino acids that push its molecular weight to $150 \mathrm{kDa}$ (referred to as AKAP150 from here forth). The additional amino acids in AKAP150 comprise a series of multiple repeats that have no significant effect on scaffolding actions, and may have been evolutionarily contracted down to the human AKAP79 analog. Multiple research groups have since identified a myriad of substrates and enzymes that AKAP scaffolds together to establish organized and efficient signal transduction. In terms of enzymes, AKAP150 is anchored predominantly at the plasma membrane in multiple cell types, including neurons, and scaffolds PKA, Protein kinase C (PKC), and calcineurin (CaN, PP2B) (Coghlan et al., 1995) along discrete sections of its secondary structure (Hoshi et al., 2005). These enzymes are then able to efficiently act upon membrane targets that AKAP150 is reported to associate with, including the NMDA receptor (Colledge et al., 2000), $\alpha$-amino-3-hydroxy-5-methyl-4isoxazolepropionic acid (AMPA) receptor (Colledge et al., 2000), Kv7.2/KCNQ2 potassium channel (Hoshi et al., 2003), and L-type voltage-gated calcium channels (Gao et al., 1997). Recent work by several labs has also confirmed AKAP150 association with TRP channels, including TRPV1 (Jeske et al., 2008; Schnizler et al., 2008; Zhang et al., 2008). This scaffolding association affords sensory neurons with the plasticity required to dynamically respond to various stimuli known to cause pain.
The first link between AKAP150 and TRPV1 was established in experiments investigating PKA catalytic subunit proximity to neuronal plasma membranes following administration of inflammatory mediators (Rathee et al., 2002). TRPV1 was found to act as the PKA-sensitive heat transducer responsible for inflammatory hypersensitivity to a thermal stimulus, although the hypersensitivity was itself sensitive to St-Ht31, a peptide that blocks PKA association with AKAP150. Indeed, forskolin-dependent sensitization of TRPV1 currents in dorsal root ganglia (DRG) neurons was blocked following pre-incubation with St-Ht31, suggesting that AKAP150 exists as part of the TRPV1-signaling module that mediates inflammatory sensitization of the channel. Although reports at that time were unable to demonstrate a physical interaction between $\mathrm{G} \alpha_{\mathrm{s}}$ subunit, AKAP150, and TRPV1 in any model system, the significance was established that scaffolding proteins dynamically affected receptor sensitivities to pro-algesic effectors.

AKAP scaffolds support multiple enzymes to modify substrate proteins in specific sub-cellular compartments. While some AKAP scaffolds bind enzymes including phosphodiesterase 4 D3 (PDE4D3) (Dodge et al., 2001; Tasken et al., 2001), protein kinase N (Takahashi et al., 1999), and protein phosphatase 2A (Takahashi et al., 1999), AKAP150 primarily orients PKA, $\mathrm{PKC}$, and $\mathrm{CaN}$ with plasma membrane substrates, including TRPV1 (Figure 2). siRNA knock-down and genetic ablation studies indicate that the loss of AKAP150 impairs PKA- and PKC-phosphorylation and sensitization of TRPV1 (Jeske et al., 2008, 2009), indicating that AKAP150 expression is essential to certain inflammatory signaling pathways that utilize these two kinases, including prostaglandin (Schnizler et al., 2008) and bradykinin (Zhang et al., 2008) receptor-activated pathways. However, de-phosphorylation and desensitization of TRPV1 by

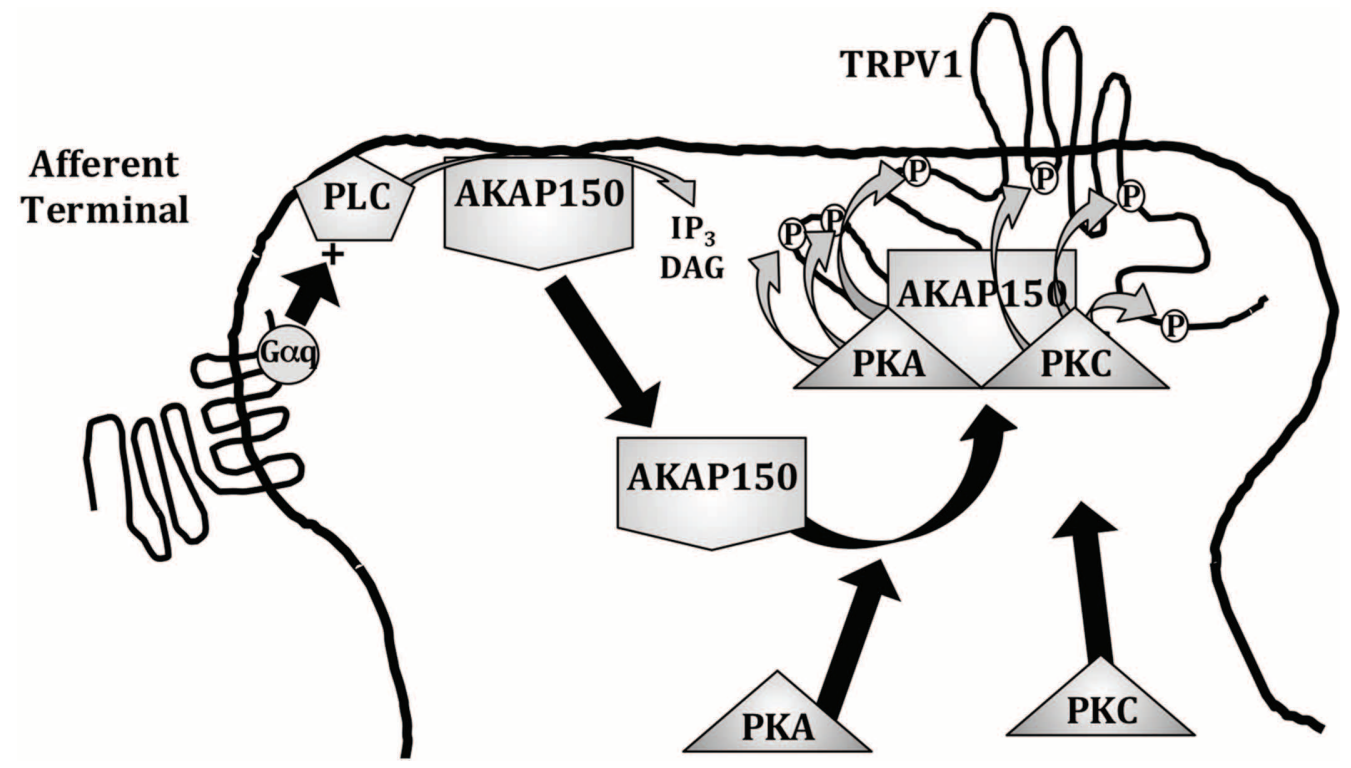

FIGURE 2 | AKAP 79/150 scaffolding at afferent terminals. AKAP 79/150 (AKAP150) is natively anchored to the plasma membrane via $\mathrm{PIP}_{2}$ linkages that are hydrolyzed following phospholipase $\mathrm{C}(\mathrm{PLC})$ activation, releasing
AKAP150 to associate with substrate receptors, such as TRPV1. AKAP150 association with TRPV1 allows for PKA- and PKC-mediated phosphorylation and sensitization of the receptor to peripheral stimuli. 
CaN (Docherty et al., 1996; Jeske et al., 2006b) is not dependent upon AKAP150 (Por et al., 2010), suggesting that $\mathrm{CaN}$ may be attracted to TRPV1 by other means, including calmodulin (Numazaki et al., 2003). Although kinase scaffolding by AKAP150 has been repeatedly demonstrated to regulate TRPV1 activation by multiple stimuli, later studies demonstrate cellular mechanisms that dictate AKAP150:TRPV1 association in sensory neurons.

Later work in this field would not only demonstrate physical association between AKAP150 and TRPV1 in multiple cell models, but also show that the association is dynamic and controlled by intracellular factors. Several research groups have provided indirect evidence of physical protein-protein interaction(s) between AKAP150 and TRPV1 including coimmunoprecipitation from transfected homologous cell culture models as well as primary sensory neuron cultures (Jeske et al., 2008; Schnizler et al., 2008; Zhang et al., 2008). Additional total internal reflective fluorescence-Forster resonance energy transfer (TIRF-FRET) findings indicate strong association at the plasma membrane in co-transfected cells (Chaudhury et al., 2011). Importantly, TIRF-FRET studies also demonstrate that AKAP150 association with TRPV1 is a calcium-sensitive process, revealing that calcium-bound calmodulin significantly reduces TRPV1 interaction with the scaffolding protein (Chaudhury et al., 2011). This dissociative interaction between calmodulin:TRPV1 and AKAP150:TRPV1 likely exists as an endogenous desensitization mechanism, allowing for calcium-sensitive, calmodulin-bound $\mathrm{CaN}$ to associate with and de-phosphorylate TRPV1, while blocking AKAP150-bound PKA and PKC from phosphorylating and re-sensitizing TRPV1. AKAP150 association with TRPV1 is also negatively controlled by the anchoring of the scaffolding protein to phosphatidylinositol-4,5-bisphosphate $\left(\mathrm{PIP}_{2}\right)$ in the plasma membrane. Working from the previously described anchorage of AKAP150 with certain phosphoinositides (Dell'Acqua et al., 1998), recent findings indicate that phospholipase C (PLC) activation releases AKAP150 from its plasma membrane moorings by hydrolyzing $\mathrm{PIP}_{2}$ into $\mathrm{IP}_{3}$ and diacylglycerol (DAG). Released AKAP150 is then free to associate with membrane-associated proteins, such as TRPV1 (Jeske et al., 2011), thereby providing an explanation for the diverging roles for $\mathrm{PIP}_{2}$ in TRPV1 regulation (Prescott and Julius, 2003; Lukacs et al., 2007; Rohacs, 2007).

\section{LIPID RAFTS}

Although Homer and AKAP scaffolds work similarly to dictate protein-protein interactions within both subcellular and temporal foci, there are several types of scaffolds that are devoid of protein structure, yet similarly organize and mediate signal transduction. Organized structures within the plasma membrane such as caveolae and lipid rafts serve to regulate the activation efficiencies of certain receptors by scaffolding these receptors and/or effector molecules to dictate intracellular signal transduction. Therefore, protein-lipid interactions are as important as protein-protein interactions in influencing afferent plasticity.

The fluid-mosaic model for biological plasma membrane organization proposed by Singer and Nicholson 40 years ago (Singer and Nicolson, 1972) has been modified in recent years with the discovery and characterization of lipid raft microdomains (Simons and Ikonen, 1997). Lipid rafts consist of densely packed cholesterol and sphingolipid moieties that impart a reduced specific density compared to adjacent plasma membrane constituents. For certain receptor complexes, lipid rafts serve to concentrate extracellular-to-intracellular communication, thereby focusing signaling cascades. Indeed, certain receptors and signaling molecules associate with lipid raft microdomains, providing for energy efficient signal transduction. In this vein, lipid rafts can be considered scaffolding structures for organizing receptor activation, as the activation of certain receptor complexes by somatosensory stimuli have been demonstrated to be dependent upon lipid raft association. Importantly, the dynamic association/dissociation of receptors and down-stream effectors with lipid rafts constitute a role in the dynamic synaptic plasticity of afferent pain transduction.

TRP channel function in both trigeminal ganglia (TG) and DRG neurons is reported to be sensitive to cholesterol depletion (reducing lipid raft integrity). In cultured DRG neurons, cholesterol depletion by methyl- $\beta$-cyclodextrin resulted in a significant reduction in capsaicin-induced currents (Liu et al., 2003), a TRPV1-specific response. Further, similar treatments to reduce cholesterol in TG neurons resulted in decreased calcium uptake following capsaicin or resiniferatoxin application in culture (Szoke et al., 2010). The cold sensing channel TRPM8 also associates with lipid rafts (Morenilla-Palao et al., 2009), and differentially reacts to cold and menthol stimuli depending on channel association with the cholesterol-laden microdomains in DRG neurons. Taken together, data suggest that TRP channel association with lipid rafts affects channel activities (Figure 3). Interestingly, TRP channels are composed of multiple plasma membrane-spanning domains, negating the need for lipid raft association to target the channels to the extracellular surface. However, N-terminal prenylation of TRPM8 was found to regulate most of the channel association with lipid rafts, further indicating that association with lipid rafts may be dynamic, and that other biochemical forces dictate channel localization to these cholesterol microdomains.

G-protein coupled receptor (GPCR) complexes also demonstrate associative properties with lipid raft moieties (Navratil et al., 2003; Chini and Parenti, 2004; Monastyrskaya et al., 2005), as well as G-protein association (Ross, 1995). Given the role of $\mu$-opioid receptor (MOR) in effectively reducing somatic pain, reported data demonstrating MOR association with lipid rafts proves to be highly significant. Work from the Law research group illustrates that association of the receptor with lipid raft microdomains (Figure 3) is affected by ligand specificity, demonstrating that etorphine induces receptor translocation out of lipid rafts, while morphine has no effect (Zheng et al., 2008). Receptor localization was found to be dependent upon association with its $\mathrm{G} \alpha_{\mathrm{i} 2}$ signaling molecule, such that agonist activation of MOR stimulates translocation to non-raft plasma membrane domains. However, etorphine agonism, which strongly promotes MOR association with $\beta$-arrestin, stimulates receptor complex dissociation from lipid rafts, while morphine agonism, which weakly promotes receptor association with $\beta$-arrestin (Whistler and von Zastrow, 1998), results in MOR re-association with $\mathrm{G} \alpha_{\mathrm{i} 2}$ in lipid rafts. Therefore, in the case of MOR, dynamic association with 


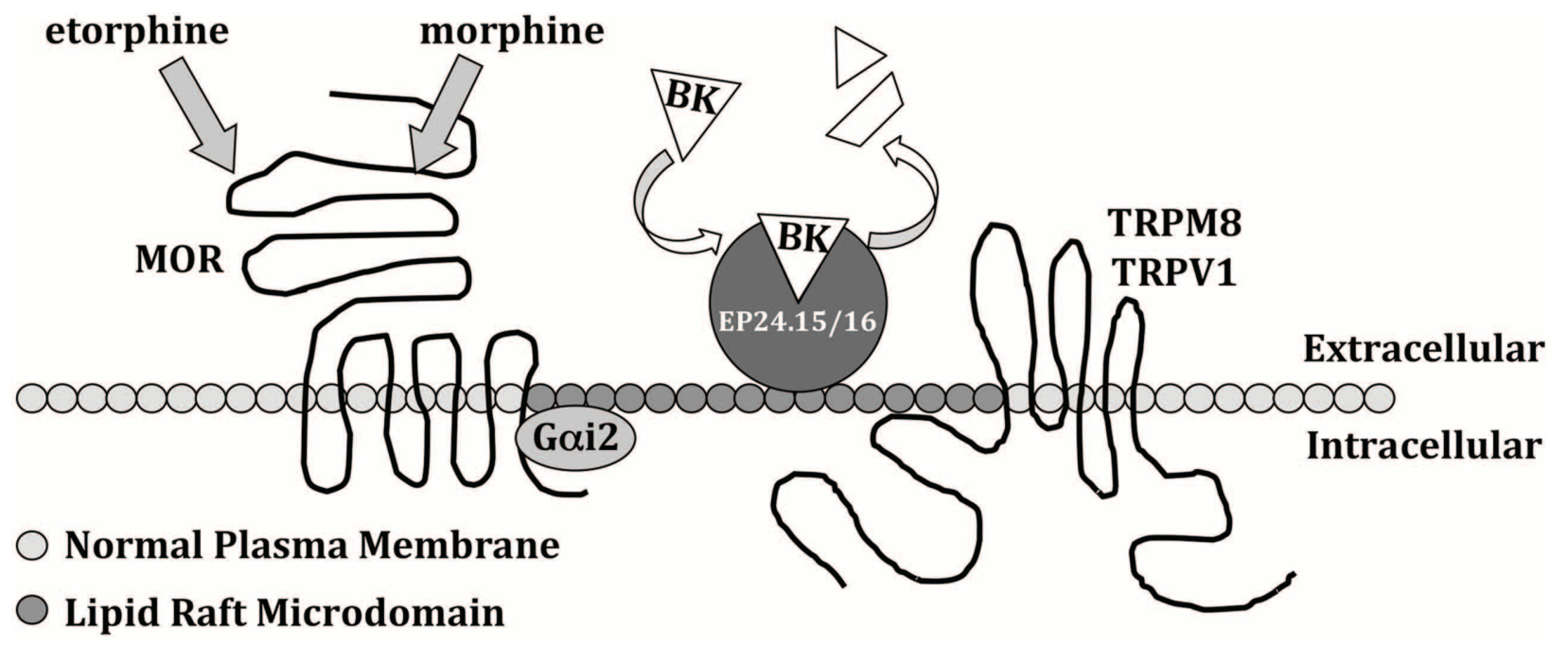

FIGURE 3 | Lipid raft scaffolding at plasma membranes. Lipid rafts centralize signal transduction through certain receptors, including the $\mu$-opioid receptor (MOR), TRPM8 and TRPV1, via their intracellular association with microdomains concentrated in cholesterol and sphingolipids. Lipid rafts also anchor extracellular peptidases EP24.15/16, to metabolize neuropeptides such as bradykinin (BK), reducing free extracellular content available for receptor activation. and internalization by $\beta$-arrestin dictates GPCR activation and propagation of signal, in so much that dynamic association of MOR with lipid rafts maintains receptor quiescence, while dissociation from lipid rafts allows for proper signal transduction downstream.

In addition to receptors intracellularly associated with lipid rafts, certain proteins are also extracellularly bound to raft microdomains, and constitute important regulators of neuropeptide functions. Metalloendopeptidases EC 3.4.24.15 and EC 3.4.24.16 (EP24.15/16) are two closely related peptidases that colocalize with bradykinin type-2 receptors (B2Rs) in lipid raft domains in TG neurons (Jeske et al., 2006a). Among the many substrates that EP24.15/16 are capable of degrading, bradykinin (BK) exists as a high affinity substrate (Rioli et al., 1998). Therefore, the extracellular tethering of EP24.15/16 allows for the peptidases to degrade free BK before it can bind to and activate lipid-raft-associated B2R (Gomez et al., 2011). Given the role of BK as an inflammatory mediator that sensitizes numerous TRP channels to normally-innocuous stimuli, lipid raft association of the receptor, as well as extracellular EP24.15/16, provide for a dynamic micro-environment capable of significantly influencing afferent somatic activation.

\section{REFERENCES}

Babu, K., Cai, Y., Bahri, S., Yang, X., and Chia, W. (2004). Roles of Bifocal, Homer, and F-actin in anchoring Oskar to the posterior cortex of Drosophila oocytes. Genes Dev. 18, 138-143.

Bottai, D., Guzowski, J. F., Schwarz, M. K., Kang, S. H., Xiao, B., Lanahan, A., Worley, P. F., and Seeburg, P. H. (2002). Synaptic activity-induced conversion of intronic to exonic sequence in Homer 1 immediate early gene expression. J. Neurosci. $22,167-175$.

Brakeman, P. R., Lanahan, A. A., O’Brien, R., Roche, K., Barnes, C. A., Huganir, R. L., and Worley, P. F. (1997). Homer: a protein that selectively binds metabotropic glutamate receptors. Nature 386, 284-288.

Bregman, D. B., Hirsch, A. H., and Rubin, C. S. (1991). Molecular characterization of bovine brain P75,

\section{CONCLUSION}

Dynamic changes in somatosensory perception occur in many subcellular locales, including the plasma membrane, through the reorganization and redistribution of proteins and scaffolding complexes. Post-translational changes target transducers of environmental stimuli that typically inform an organism that danger and/or injury is present. These receptor transducers serve as substrates and points of control in multiple pathways, and scaffolding structures maintain dynamic, yet strict energy-efficient control over reactions that significantly affect receptor response. Although scaffolding structures exist as large membrane-associated proteins, as well as microdomains within the membranes themselves. Both structures function to provide a framework to support and regulate dynamic changes to transducers of somatosensory information, prompting continued research into the roles of scaffolding proteins and structures in injury and disease pathologies.

\section{ACKNOWLEDGMENTS}

Nathaniel A. Jeske is supported by NINDS NS061884. We thank Matthew P. Rowan and Elaine D. Por for critical discussions concerning this review manuscript.

a high affinity binding protein for the regulatory subunit of cAMPdependent protein kinase II beta. J. Biol. Chem. 266, 7207-7213.

Carr, D. W., Stofko-Hahn, R. E. Fraser, I. D., Cone, R. D., and Scott, J. D. (1992). Localization of the cAMP-dependent protein kinase to the postsynaptic densities by A-kinase anchoring proteins. Characterization of AKAP 79. J. Biol. Chem. 267, 16816-16823.
Chaudhury, S., Bal, M., Belugin, S., Shapiro, M. S., and Jeske, N. A. (2011). AKAP150-mediated TRPV1 sensitization is disrupted by calcium/calmodulin. Mol. Pain 7, 34.

Chini, B., and Parenti, M. (2004). Gprotein coupled receptors in lipid rafts and caveolae: how, when and why do they go there? J. Mol. Endocrinol. 32, 325-338.

Coghlan, V. M., Perrino, B. A., Howard, M., Langeberg, L. K., Hicks, J. B., 
Gallatin, W. M., and Scott, J. D. (1995). Association of protein kinase $\mathrm{A}$ and protein phosphatase $2 \mathrm{~B}$ with a common anchoring protein. Science 267, 108-111.

Colledge, M., Dean, R. A., Scott, G. K., Langeberg, L. K., Huganir, R. L., and Scott, J. D. (2000). Targeting of PKA to glutamate receptors through a MAGUK-AKAP complex. Neuron $27,107-119$

Dell'Acqua, M. L., Faux, M. C., Thorburn, J., Thorburn, A., and Scott, J. D. (1998). Membranetargeting sequences on AKAP79 bind phosphatidylinositol-4,5bisphosphate. EMBO J. 17, 2246-2260.

Docherty, R. J., Yeats, J. C., Bevan, S., and Boddeke, H. W. (1996). Inhibition of calcineurin inhibits the desensitization of capsaicinevoked currents in cultured dorsal root ganglion neurones from adult rats. Pflugers Arch. 431, 828-837.

Dodge, K. L., Khouangsathiene, S., Kapiloff, M. S., Mouton, R., Hill, E. V., Houslay, M. D., Langeberg, L. K., and Scott, J. D. (2001). mAKAP assembles a protein kinase A/PDE4 phosphodiesterase cAMP signaling module. EMBO J. 20, 1921-1930.

Emes, R. D., Pocklington, A. J., Anderson, C. N., Bayes, A., Collins, M. O., Vickers, C. A., Croning, M. D., Malik, B. R., Choudhary, J. S., Armstrong, J. D., and Grant, S. G. (2008). Evolutionary expansion and anatomical specialization of synapse proteome complexity. Nat. Neurosci. 11, 799-806.

Gao, T., Yatani, A., Dell'Acqua, M. L., Sako, H., Green, S. A., Dascal, N., Scott, J. D., and Hosey, M. M. (1997). cAMP-dependent regulation of cardiac L-type $\mathrm{Ca}^{2+}$ channels requires membrane targeting of PKA and phosphorylation of channel subunits. Neuron 19, 185-196.

Gomez, R., Por, E. D., Berg, K. A., Clarke, W. P., Glucksman, M. J., and Jeske, N. A. (2011). Metallopeptidase inhibition potentiates bradykinin-induced hyperalgesia. Pain 152, 1548-1554.

Guo, W., Wei, F., Zou, S., Robbins, M. T., Sugiyo, S., Ikeda, T., Tu, J. C., Worley, P. F., Dubner, R., and Ren, K. (2004). Group I metabotropic glutamate receptor NMDA receptor coupling and signaling cascade mediate spinal dorsal horn NMDA receptor $2 \mathrm{~B}$ tyrosine phosphorylation associated with inflammatory hyperalgesia. J. Neurosci. 24, 9161-9173.

Hoshi, N., Langeberg, L. K., and Scott, J. D. (2005). Distinct enzyme combinations in AKAP signalling complexes permit functional diversity. Nat. Cell Biol. 7, 1066-1073.

Hoshi, N., Zhang, J. S., Omaki, M., Takeuchi, T., Yokoyama, S., Wanaverbecq, N., Langeberg, L. K., Yoneda, Y., Scott, J. D., Brown, D. A., and Higashida, H. (2003). AKAP150 signaling complex promotes suppression of the M-current by muscarinic agonists. Nat. Neurosci. 6, 564-571.

Jeske, N. A., Berg, K. A., Cousins, J. C., Ferro, E. S., Clarke, W. P., Glucksman, M. J., and Roberts, J. L. (2006a). Modulation of bradykinin signaling by EP24.15 and EP24.16 in cultured trigeminal ganglia. $J$. Neurochem. 97, 13-21.

Jeske, N. A., Diogenes, A., Ruparel, N. B., Fehrenbacher, J. C., Henry, M., Akopian, A. N., and Hargreaves, K. M. (2008). A-kinase anchoring protein mediates TRPV1 thermal hyperalgesia through PKA phosphorylation of TRPV1. Pain 138, 604-616.

Jeske, N. A., Patwardhan, A. M. Gamper, N., Price, T. J., Akopian, A. N., and Hargreaves, K. M. (2006b). Cannabinoid WIN 55,212-2 regulates TRPV1 phosphorylation in sensory neurons. J. Biol. Chem. 281, 32879-32890.

Jeske, N. A., Patwardhan, A. M., Ruparel, N. B., Akopian, A. N., Shapiro, M. S., and Henry, M. A. (2009). A-kinase anchoring protein 150 controls protein kinase C-mediated phosphorylation and sensitization of TRPV1. Pain 146, 301-307.

Jeske, N. A., Por, E. D., Belugin, S., Chaudhury, S., Berg, K. A., Akopian, A. N., Henry, M. A., and Gomez, R. (2011). A-kinase anchoring protein 150 mediates transient receptor potential family $\mathrm{v}$ type 1 sensitivity to phosphatidylinositol4,5-bisphosphate. J. Neurosci. 31, 8681-8688.

Ji, R. R., Samad, T. A., Jin, S. X. Schmoll, R., and Woolf, C. J. (2002). p38 MAPK activation by NGF in primary sensory neurons after inflammation increases TRPV1 levels and maintains heat hyperalgesia. Neuron 36, 57-68.

Kato, A., Ozawa, F., Saitoh, Y., Hirai, K., and Inokuchi, K. (1997). vesl, a gene encoding VASP/Ena family related protein, is upregulated during seizure, long-term potentiation and synaptogenesis. FEBS Lett. 412, 183-189.

Kolber, B. J., Montana, M. C., Carrasquillo, Y., Xu, J., Heinemann, S. F., Muglia, L. J., and Gereau, R. W. T. (2010). Activation of metabotropic glutamate receptor
5 in the amygdala modulates pain-like behavior. J. Neurosci. 30 8203-8213.

Li, M., Liu, J., and Zhang, C. (2011a). Evolutionary history of the vertebrate mitogen activated protein kinases family. PLoS One 6, e26999. doi: 10.1371/journal.pone.0026999

Li, Z., Ji, G., and Neugebauer, V. (2011b). Mitochondrial reactive oxygen species are activated by mGluR5 through IP3 and activate ERK and PKA to increase excitability of amygdala neurons and pain behavior. J. Neurosci. 31 1114-1127.

Liu, B., Hui, K., and Qin, F. (2003). Thermodynamics of heat activation of single capsaicin ion channels VR1. Biophys. J. 85, 2988-3006.

Lukacs, V., Thyagarajan, B., Varnai, P., Balla, A., Balla, T., and Rohacs, T. (2007). Dual regulation of TRPV1 by phosphoinositides. J. Neurosci. 27, 7070-7080.

Ma, Z. L., Zhu, W., Zhang, W., and Gu, X. P. (2009). Effect of the synaptic scaffolding protein Homerla on chronic compression of dorsal root ganglion. Ann. Clin. Lab. Sci. 39, 71-75.

Monastyrskaya, K., Hostettler, A., Buergi, S., and Draeger, A. (2005). The NK1 receptor localizes to the plasma membrane microdomains, and its activation is dependent on lipid raft integrity. J. Biol. Chem. 280, 7135-7146.

Morenilla-Palao, C., Pertusa, M., Meseguer, V., Cabedo, H., and Viana, F. (2009). Lipid raft segregation modulates TRPM8 channel activity. J. Biol. Chem. 284 9215-9224.

Navratil, A. M., Bliss, S. P., Berghorn, K. A., Haughian, J. M., Farmerie, T. A., Graham, J. K., Clay, C. M., and Roberson, M. S. (2003). Constitutive localization of the gonadotropin-releasing hormone (GnRH) receptor to low density membrane microdomains is necessary for GnRH signaling to ERK. J. Biol. Chem. 278, 31593-31602.

Neugebauer, V., Li, W., Bird, G. C., Bhave, G., and Gereau, R. W. T. (2003). Synaptic plasticity in the amygdala in a model of arthritic pain: differential roles of metabotropic glutamate receptors 1 and 5. J. Neurosci. 23, 52-63.

Numazaki, M., Tominaga, T., Takeuchi, K., Murayama, N., Toyooka, H., and Tominaga, M. (2003). Structural determinant of TRPV1 desensitization interacts with calmodulin. Proc. Natl. Acad. Sci. U.S.A. 100, 8002-8006.
Por, E. D., Samelson, B. K., Belugin, S., Akopian, A. N., Scott, J. D., and Jeske, N. A. (2010). PP2B/calcineurin-mediated desensitization of TRPV1 does not require AKAP150. Biochem. J. 432, 549-556.

Prescott, E. D., and Julius, D. (2003). A modular PIP2 binding site as a determinant of capsaicin receptor sensitivity. Science 300, 1284-1288.

Rathee, P. K., Distler, C., Obreja, O., Neuhuber, W., Wang, G. K., Wang, S. Y., Nau, C., and Kress, M. (2002). PKA/AKAP/VR-1 module: a common link of Gs-mediated signaling to thermal hyperalgesia. J. Neurosci. 22, 4740-4745.

Rioli, V., Kato, A., Portaro, F. C., Cury, G. K., Te Kaat, K., Vincent, B., Checler, F., Camargo, A. C., Glucksman, M. J., Roberts, J. L. Hirose, S., and Ferro, E. S. (1998). Neuropeptide specificity and inhibition of recombinant isoforms of the endopeptidase 3.4.24.16 family: comparison with the related recombinant endopeptidase 3.4.24.15 Biochem. Biophys. Res. Commun. 250, 5-11.

Rohacs, T. (2007). Regulation of TRP channels by PIP(2). Pflugers Arch. 453, 753-762.

Ross, E. M. (1995). Protein modification. Palmitoylation in G-protein signaling pathways. Curr. Biol. 5, 107-109.

Schnizler, K., Shutov, L. P., Van Kanegan, M. J., Merrill, M. A., Nichols, B., Mcknight, G. S., Strack, S., Hell, J. W., and Usachev, Y. M. (2008). Protein kinase A anchoring via AKAP150 is essential for TRPV1 modulation by forskolin and prostaglandin E2 in mouse sensory neurons. J. Neurosci. 28, 4904-4917.

Simons, K., and Ikonen, E. (1997). Functional rafts in cell membranes. Nature 387, 569-572.

Singer, S. J., and Nicolson, G. L. (1972). The fluid mosaic model of the structure of cell membranes. Science 175 , 720-731.

Stiber, J. A., Tabatabaei, N., Hawkins, A. F., Hawke, T., Worley, P. F., Williams, R. S., and Rosenberg, P. (2005). Homer modulates NFAT-dependent signaling during muscle differentiation. Dev. Biol. 287, 213-224.

Szoke, E., Borzsei, R., Toth, D. M., Lengl, O., Helyes, Z., Sandor, Z., and Szolcsanyi, J. (2010). Effect of lipid raft disruption on TRPV1 receptor activation of trigeminal sensory neurons and transfected cell line. Eur. J. Pharmacol. 628, 67-74.

Tadokoro, S., Tachibana, T., Imanaka, T., Nishida, W., and Sobue, K. 
(1999). Involvement of unique leucine-zipper motif of PSD-Zip45 (Homer 1c/vesl-1L) in group 1 metabotropic glutamate receptor clustering. Proc. Natl. Acad. Sci. U.S.A. 96, 13801-13806.

Takahashi, M., Shibata, H., Shimakawa, M., Miyamoto, M., Mukai, H., and Ono, Y. (1999). Characterization of a novel giant scaffolding protein, CG-NAP, that anchors multiple signaling enzymes to centrosome and the golgi apparatus. J. Biol. Chem. 274, 17267-17274.

Tappe, A., Klugmann, M., Luo, C., Hirlinger, D., Agarwal, N., Benrath, J., Ehrengruber, M. U., During, M. J., and Kuner, R. (2006). Synaptic scaffolding protein Homerla protects against chronic inflammatory pain. Nat. Med. 12, 677-681.

Tappe-Theodor, A., Fu, Y., Kuner, R., and Neugebauer, V. (2011). Homerla signaling in the amygdala counteracts pain-related synaptic plasticity, mGluR1 function and pain behaviors. Mol. Pain 7, 38 .

Tasken, K. A., Collas, P., Kemmner, W. A., Witczak, O., Conti,
M., and Tasken, K. (2001). Phosphodiesterase 4D and protein kinase a type II constitute a signaling unit in the centrosomal area. J. Biol. Chem. 276, 21999-22002.

Tu, J. C., Xiao, B., Yuan, J. P., Lanahan, A. A., Leoffert, K., Li, M., Linden, D. J., and Worley, P. F. (1998). Homer binds a novel proline-rich motif and links group 1 metabotropic glutamate receptors with IP3 receptors. Neuron 21, 717-726.

Vazdarjanova, A., McNaughton, B. L., Barnes, C. A., Worley, P. F., and Guzowski, J. F. (2002). Experiencedependent coincident expression of the effector immediate-early genes arc and Homer 1a in hippocampal and neocortical neuronal networks. J. Neurosci. 22, 10067-10071.

Whistler, J. L., and von Zastrow, M. (1998). Morphine-activated opioid receptors elude desensitization by beta-arrestin. Proc. Natl. Acad. Sci. U.S.A. 95, 9914-9919.

Xiao, B., Tu, J. C., Petralia, R. S., Yuan, J. P., Doan, A., Breder, C. D., Ruggiero, A., Lanahan, A. A.,
Wenthold, R. J., and Worley, P. F. (1998). Homer regulates the association of group 1 metabotropic glutamate receptors with multivalent complexes of homer-related, synaptic proteins. Neuron 21, 707-716.

Yashpal, K., Fisher, K., Chabot, J. G., and Coderre, T. J. (2001). Differential effects of NMDA and group I mGluR antagonists on both nociception and spinal cord protein kinase $\mathrm{C}$ translocation in the formalin test and a model of neuropathic pain in rats. Pain 94, 17-29.

Yuan, J. P., Kiselyov, K., Shin, D. M., Chen, J., Shcheynikov, N., Kang, S. H., Dehoff, M. H., Schwarz, M. K., Seeburg, P. H., Muallem, S., and Worley, P. F. (2003). Homer binds TRPC family channels and is required for gating of TRPC1 by IP3 receptors. Cell 114, 777-789.

Zhang, X., Li, L., and Mcnaughton, P. A. (2008). Proinflammatory mediators modulate the heat-activated ion channel TRPV1 via the scaffolding protein AKAP79/150. Neuron 59, 450-461.
Zheng, H., Chu, J., Qiu, Y., Loh, H. H., and Law, P. Y. (2008). Agonistselective signaling is determined by the receptor location within the membrane domains. Proc. Natl. Acad. Sci. U.S.A. 105, 9421-9426.

Conflict of Interest Statement: The authors declare that the research was conducted in the absence of any commercial or financial relationships that could be construed as a potential conflict of interest.

Received: 21 December 2011; accepted: 06 January 2012; published online: 23 January 2012.

Citation: Jeske NA (2012) Somatosensory scaffolding structures. Front. Mol. Neurosci. 5:2. doi: 10.3389/fnmol. 2012.00002

Copyright (c) 2012 Jeske. This is an open-access article distributed under the terms of the Creative Commons Attribution Non Commercial License, which permits non-commercial use, distribution, and reproduction in other forums, provided the original authors and source are credited. 